\title{
Comparison of Ultrasound Findings of Carpal Tunnel Syndrome before and after Corticosteroid Injection
}

\author{
Hamid Golmohammadi ${ }^{1}$, Hossein Saremi², Abbas Moradi³, Shadi Pakmehr ${ }^{4}$, Masoud \\ Esnaashari ${ }^{5 * *}$ \\ ${ }^{I}$ Assistant Professor, Department of Radiology, Besat Hospital, Hamadan University of Medical Sciences, Hamadan, Iran \\ ${ }^{2}$ Associate Professor, Department of Orthopedic Surgery, Besat Hospital, Hamadan University of Medical Sciences, \\ Hamadan, Iran \\ ${ }^{3}$ Faculty Member, Department of Community Medicine, Hamadan University of Medical Sciences, Hamadan, Iran \\ ${ }^{4}$ General Practitioner, Emergency Department, Shahid Rahimi Hospital, Lorestan University of Medical Sciences, Khorram \\ Abad, Iran \\ ${ }^{5}$ Radiologist, Department of Radiology, Besat Hospital, Hamadan University of Medical Sciences, Hamadan, Iran \\ * Corresponding Author: Masoud Esnaashari, Department of Radiology, Besat Hospital, Hamadan University of Medical
} Sciences, Hamadan, Iran. Email: masoudesnaashari@yahoo.com

Received: 09.10.2019

Accepted: 22.01 .2020

\section{How to Cite this Article:}

Golmohammadi H, Saremi H, Moradi A, Pakmehr S, Esnaashari M. Comparison of Ultrasound Findings of Carpal Tunnel Syndrome before and after Corticosteroid Injection. Avicenna J Clin Med. 2020; 26(4): 193198. DOI: $10.29252 / \mathrm{ajcm} .26$ 4.193

\section{Abstract}

Background and Objective: Carpal Tunnel Syndrome is the most prevalent type of peripheral neuropathy due to neural entrapment. This syndrome is primarily diagnosed based on clinical symptoms, and it is subsequently confirmed by electro-diagnostic studies. Ultrasonography as a safe, available, and inexpensive method is also valuable in the follow-up of patients. This study aimed to evaluate the ultrasound findings before and after local corticosteroid injection.

Materials and Methods: This interventional study was conducted on 45 patients referring to the orthopedic clinic of Besat Hospital, Hamadan, Iran, during 2017. The patients who were selected by convenient sampling method had the symptoms of carpal tunnel syndrome and were diagnosed positive based on electrodiagnostic studies indicating a moderate grade of the disease. Wrist ultrasound was performed before and after the injection of corticosteroid (two months later). Moreover, the ultrasound indices were compared before and after the injection. Data were analyzed in SPSS software (version 16). A p-value less than 0.05 was considered statistically significant.

Results: According to the results, $80 \%$ of the patients were female. Moreover, the mean age of the patients was $47.9 \pm 11.6$ years (age range: $22-$ 72 years). About $20 \%$ of the cases were left-handed. The right hand was mostly affected by carpal tunnel syndrome $(70 \%)$. After injection, there were reductions in the median nerve thickness $(\mathrm{P}=0.95)$, retinaculum thickness $(\mathrm{P}=0.001)$, and nerve cross-sectional area $(\mathrm{P}=0.001)$. The Disabilities of the Arm, Shoulder, and Hand (DASH) scale showed that the clinical symptoms of the patients were significantly reduced at the end of the study $(\mathrm{P}=0.001)$. Conclusion: Corticosteroid injection in patients with moderate severity of carpal tunnel syndrome improved the clinical symptoms and caused reductions in median nerve thickness, cross-sectional area, and flexor retinaculum thickness.

Keywords: Carpal Tunnel Syndrome, Corticosteroid, Ultrasound 


\section{مقايسه يافته هاى سونوتر افى سندرم تونل كاري، قبل و بعد از تزريق كورتيكوستروئيد}

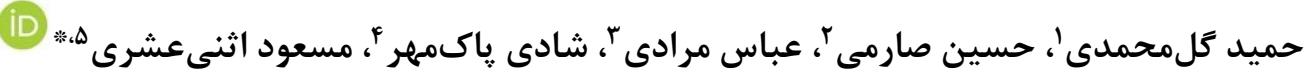

' استاديار، بخش راديولوزى، بيمارستان بعثت، دانشكاه علوم يزشكى همدان، همدان، ايران

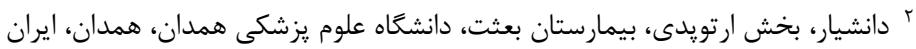

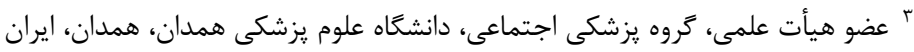

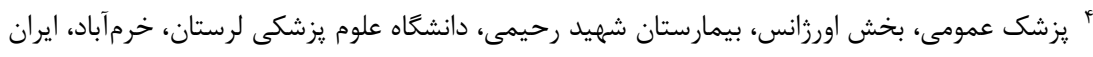

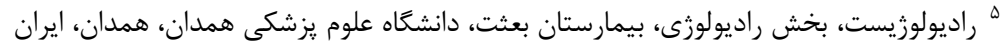
masoudesnaashari@yahoo.com : نويسنده مسئول: مسعود اثنىعشرى، بيمارستان بعثت، دانشخاه علوم بزشكى همدان، همدان، ايران. ايميل

\begin{tabular}{|c|c|}
\hline 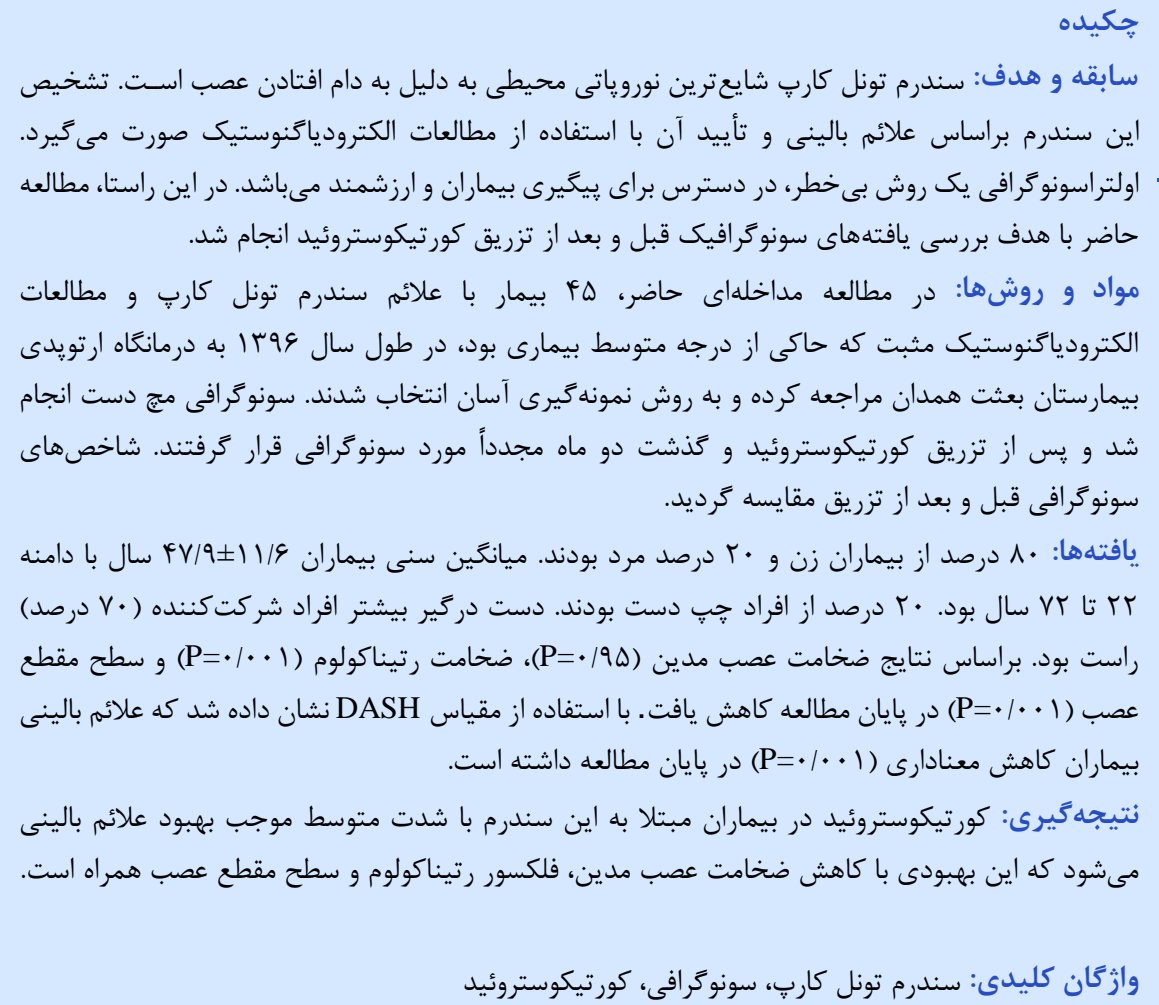 & 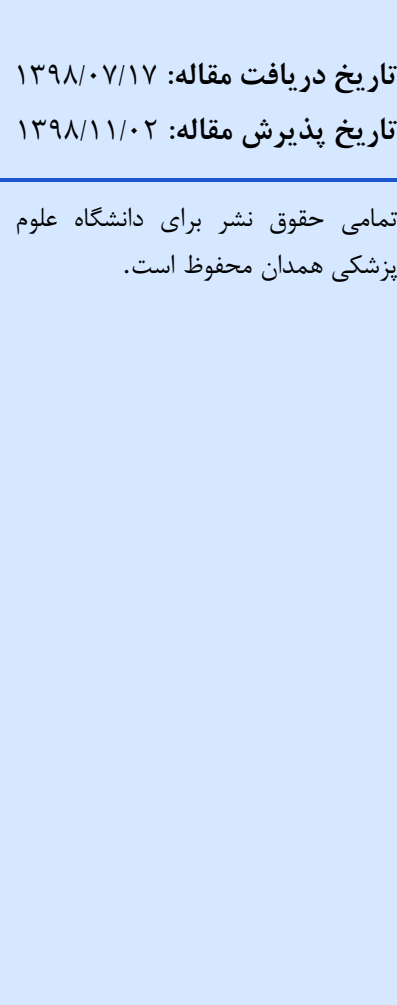 \\
\hline
\end{tabular}

قانونى اجبارى مىباشد؛ اما ييشرفتهاى حاصل از آن در فناورى

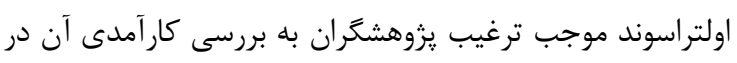

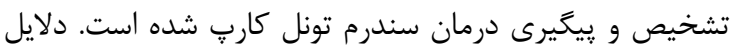

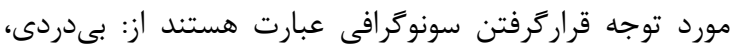

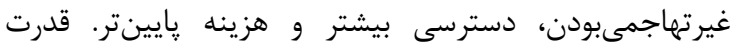

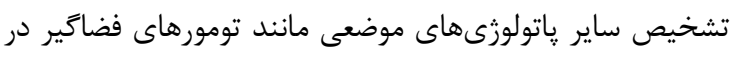

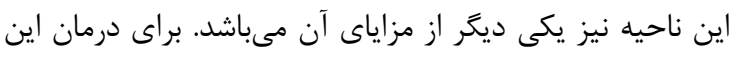

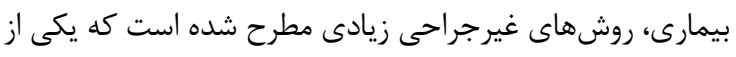
آنها تزريق كورتيكوستروئيد مىباشد. در مطالعات انجامشده بهمنظور تزريق كورتون با كايد سونو و
سندرم تونل كارب شايعترين نوع نوروياتى محيطى ناشى از به دام افتادن عصب اسـت. تشخيص اوليه سندرم تونل كارب

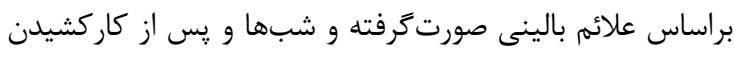

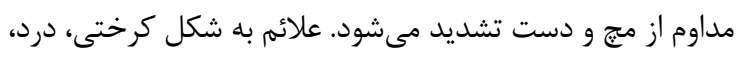
كززز در محل توزيع عصب مدين (انگشتان شست، اشاره و ميانى)

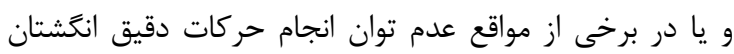

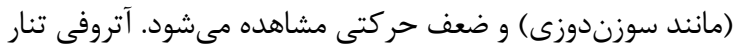
(توده عضلانى روى قاعده شست) از علائم قابل مشاهده اين اختلال

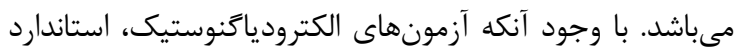

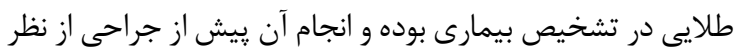


مديان (MDL) بين ه/ه تا ه/ (M) متر بر ثانيه؛ زمان تأخيرى حسى

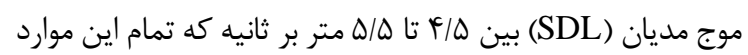
با انجام Electromyography and Nerve) EMG-NCV (Conduction Velocity

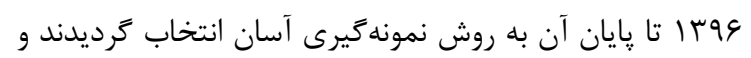

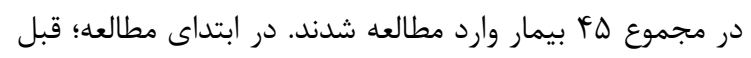

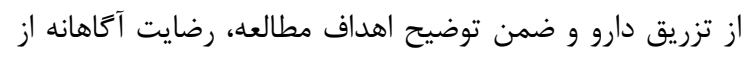

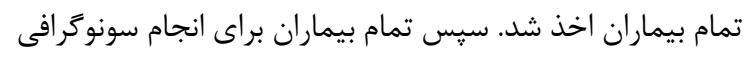

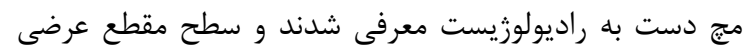

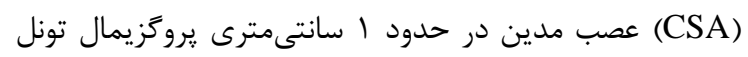

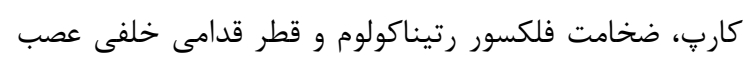

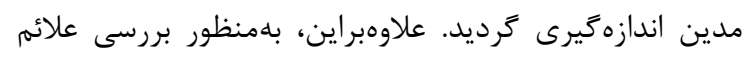

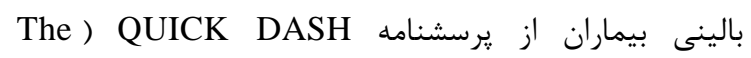
(Disabilities of the Arm, Shoulder and Hand Score استفاده شد. در اين مرحله بيماران تحت تزريق كورتون در مج

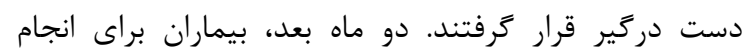

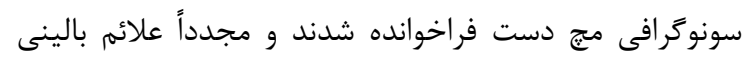
توسط DASH ارزيابى گرديد.

در ادامه، تغييرات ايجادشده قبل و بعد از تزريق كورتون در درد

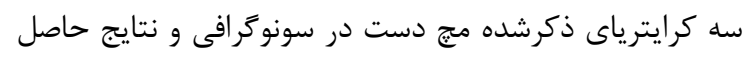

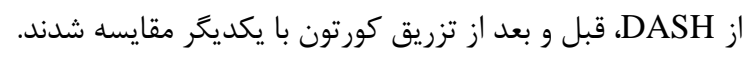

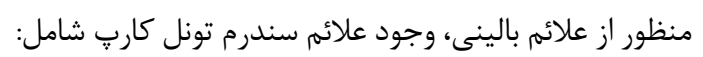

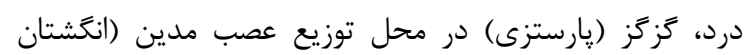

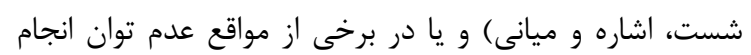

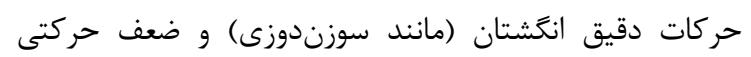

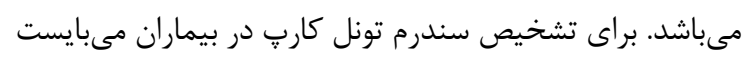

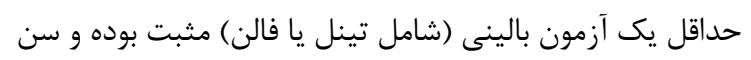

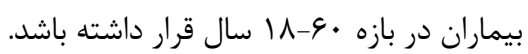

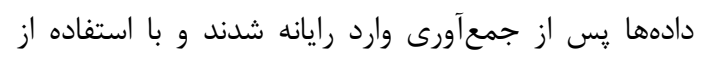

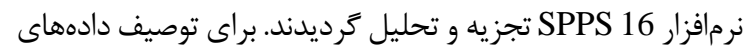

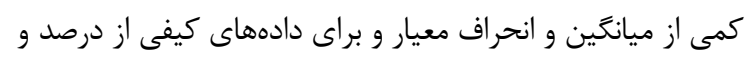

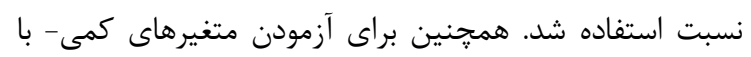

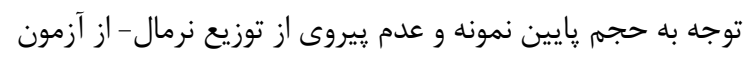
ويلكاكسون رتبه علامتدار (Wilcoxon Signed-Rank Test)

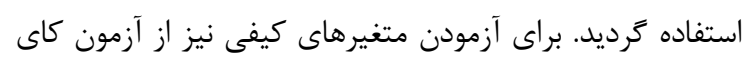

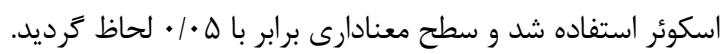

\section{يافته ها}

در اين مطالعه مداخلهاى، هل كارٍ با شدت متوسط تحت تزريق كورتون در مج دست مس مرار

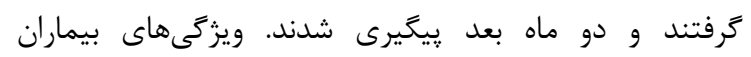

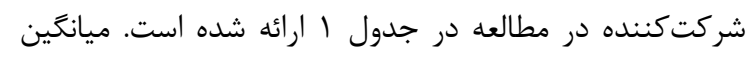

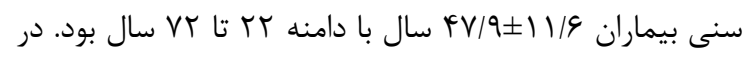
جدول r نتايج بالينى و سونوگرافى بيماران، قبل و بعد از مداخله
بدون آن مشخص كرديده است كه بهبودى قابلتوجهى در

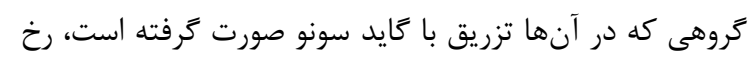

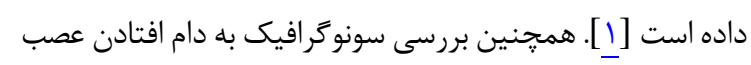
مديان در مطالعهاى مشخص نمود كه سونوگرافى يك آنى آزمون

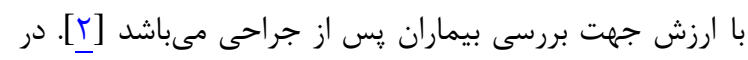

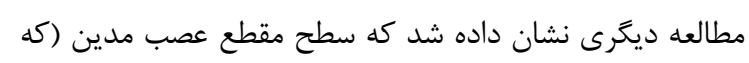

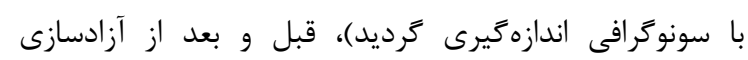

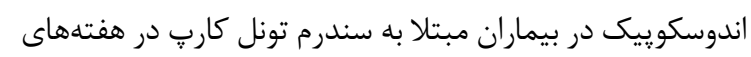

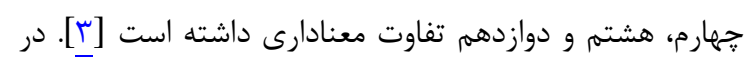

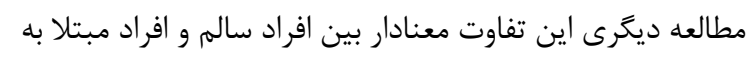

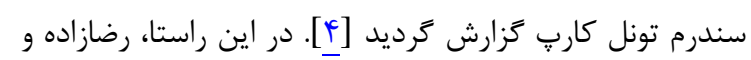

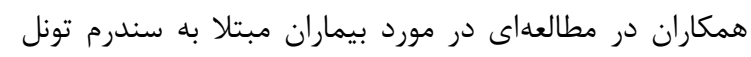

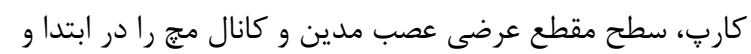

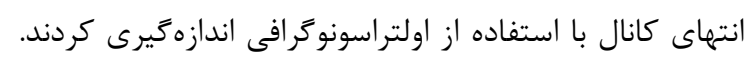

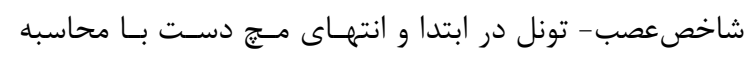

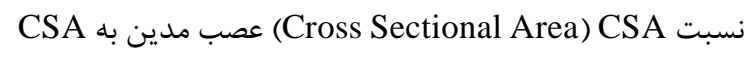
كانال مج محاسبه شد. نتايج نشان دادند كه بين دو شاخص

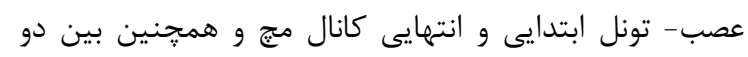
شاخص سطح مقطع عصب مدين و شاخص عصب- تونل در

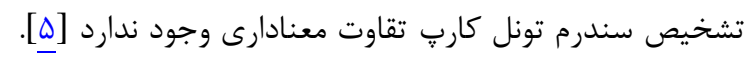

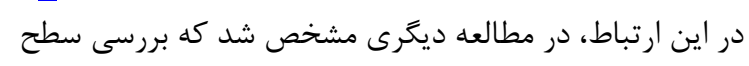

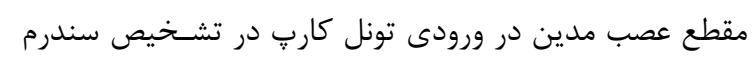

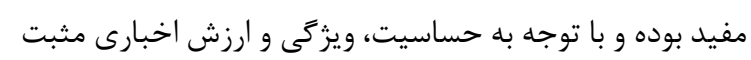

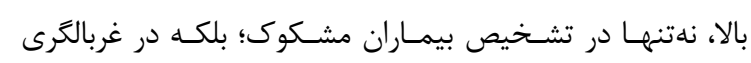

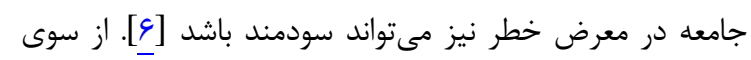

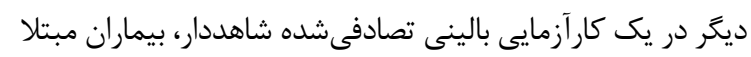

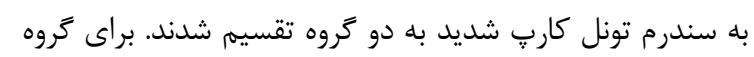

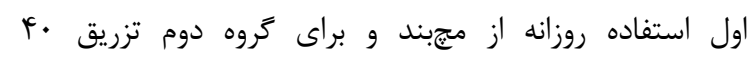
ميلى

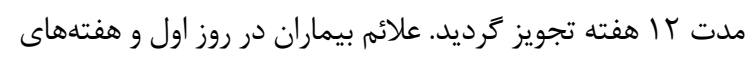

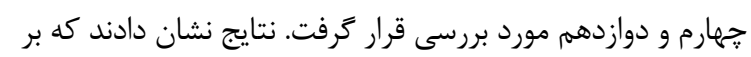
Functional Status Scale and Median Nerve اساس نورن Distal Motor Latency

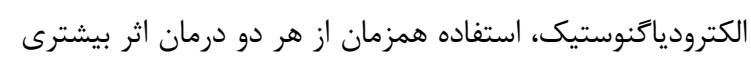

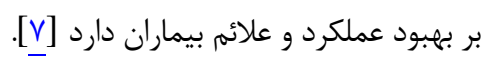

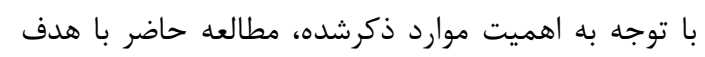

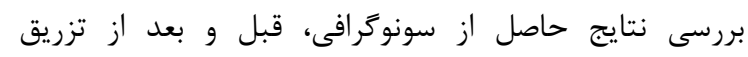

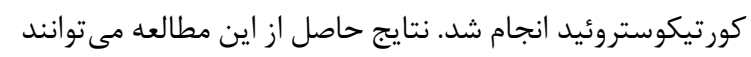
در تشخيص و رييخيرى درمان بيماران مؤثر باشند.

\section{مواد و روشها}

در مطالعه مداخلهاى حاضر (Before-after Trial) بيماران

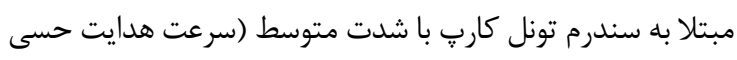

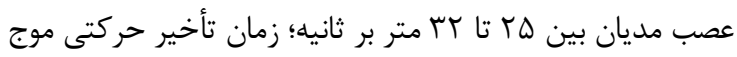


نشان داده شده است. براساس نتايج، ضخامت عصب مدين،

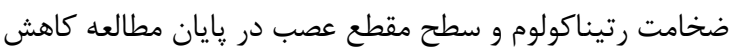

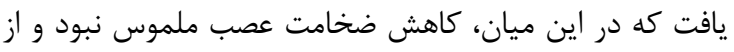

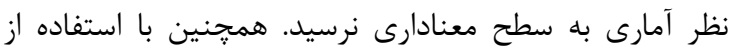

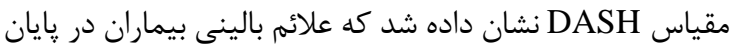
مطالعه كاهش معنادارى يافته است.
جدول ا: ويزگگىهاى بيماران شركت كننده در مطالعه

\begin{tabular}{|c|c|}
\hline فراوانى (درصد) & متغير \\
\hline$(r \cdot) q /(\Lambda \cdot) r \varphi$ & جنس (زن /مرد) \\
\hline$(Y r / Y) 1 \cdot I(V V / \Lambda) r \Delta$ & دست غالب (راست /جֶ) \\
\hline$(r \wedge / Q) \mid r /(V / / 1) r T$ & دست درگير (راست/جٍ) \\
\hline$(q \Delta / \varepsilon) F r /(\mathcal{F} / \mathcal{F}) \mathrm{r}$ & سابقه ديابت (بله /خير) \\
\hline
\end{tabular}

جدول r يافتههاى بالينى و سونوكرافى بيماران، قبل و بعد از مداخله

\begin{tabular}{|c|c|c|c|c|c|}
\hline \multirow{2}{*}{ "سطح معنادارى } & \multicolumn{2}{|c|}{ بعد از مداخله } & \multicolumn{2}{|c|}{ قبل از مداخله } & \multirow{2}{*}{ متغير } \\
\hline & انحراف معيار & ميانتين & انحراف معيار & ميانگين & \\
\hline.$/ 9 \Delta$ & .1 .9 & $1 / 9$ & $\cdot / \cdot \mathrm{F}$ & $1 / 91$ & ضخامت عصب \\
\hline$\cdot 1 \cdot \cdot 1$ & $1 \cdot r$ & $\cdot 194$ & $1 \cdot r$ & $\cdot / V V$ & ضخامت رتيناكولوم \\
\hline $.1 \cdot .1$ & $r / 1$ & N/9 & $r / \mathcal{F}$ & $9 / \pi$ & سطح مقطع عصب \\
\hline$\cdot 1 \cdot \cdot 1$ & $19 / 9$ & $r r \Delta / \Delta$ & $r) / 9$ & $r \in V / V$ & DASH \\
\hline
\end{tabular}

*Wilcoxon signed-rank test

$$
\text { براى انجام آن دارند. }
$$

نتايج مطالعه حاضر نشان دادند كه تزريق كورتيكوستروئيد در

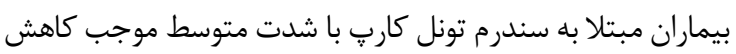

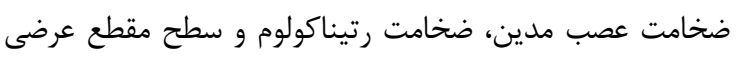

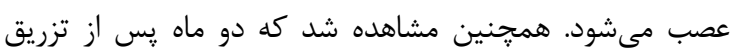

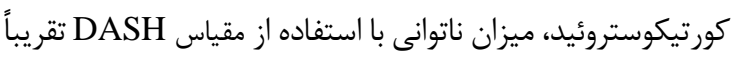
r I ا واحد بهبود ييدا كرده است كه از نظر آمارى معنادار مىباشد. كارايى تزريق موضعى كورتيكوستروئيد در درمان

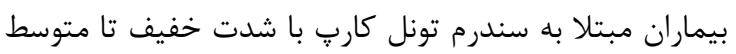

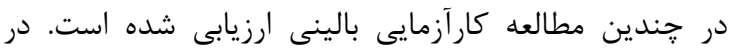

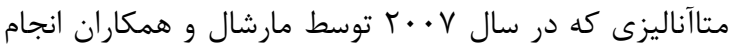

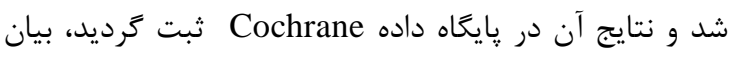
شد كه تزريق كورتيكوستروئيد در مقايسه با دارونما (يلاسبو) ديان ديان

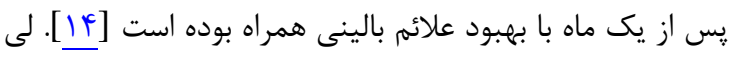

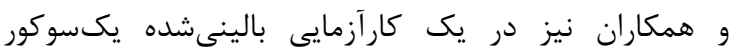

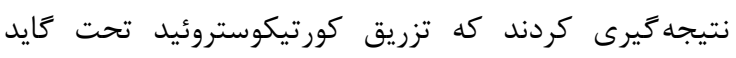

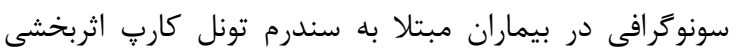

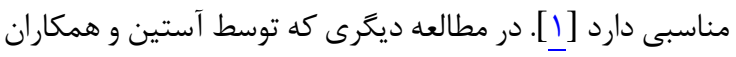
صورت كرفت، نشان داده شد كه تزريق كورتيكوستروئيد با كايد

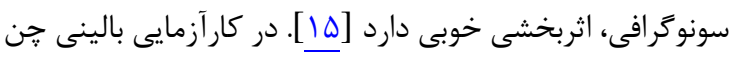

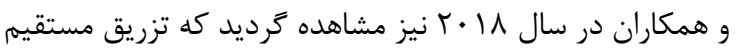

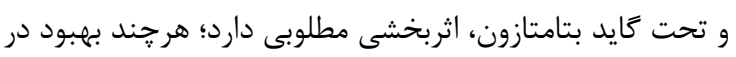

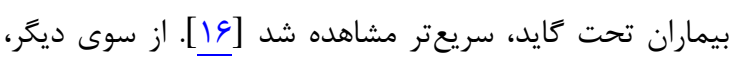
خسروى و همكاران در يك كارآزمايى بالينى تصادفى ندانده شاهددار در مورد بيماران مبتلا به سندرم تونل كارب شدي شديد بيان

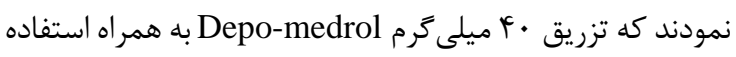

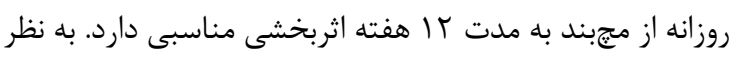

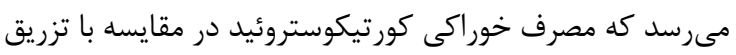

براساس دانش نويسندًان، اين مطالعه مداخلهاى نخستين مطالعه كشورى مى باشد كه به بررسى تزريق كورتيكوستروئيد

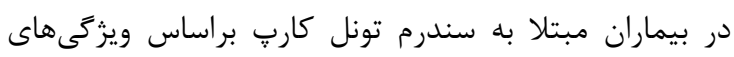

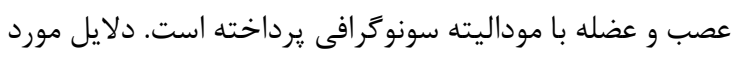

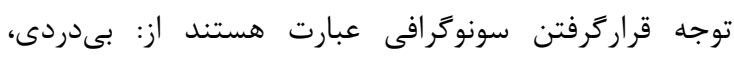
غيرتهاجمىبودن، دسترسى بيشتر و هزينه يايينتر آن. قدرت

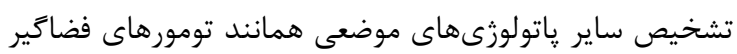

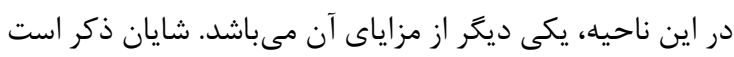

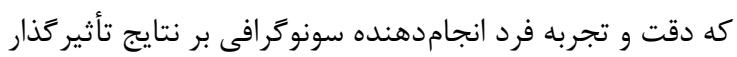

خواهد بود. - اهن شيوع بالاى ســدرم تونل كارٍ ناشى از موقعيـت خـاص

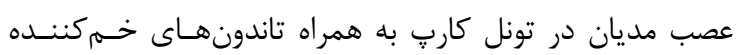

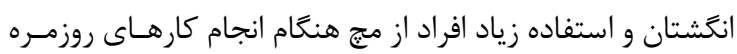
(بهويزه همراه با راست كردن مكرر مج) بوده و احتمال آسيب تونل

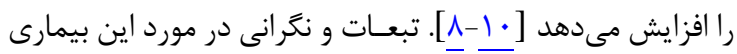

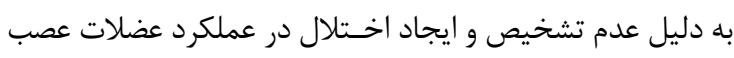

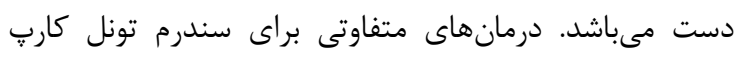

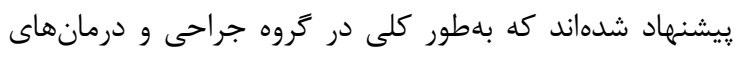

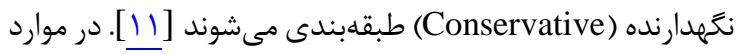
شديد، جراحى و در بيماران با شدت خفيف تا متوسط،

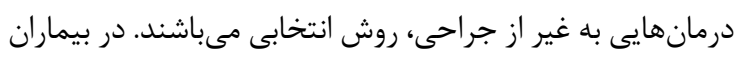

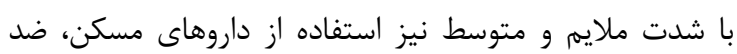
التهابهاى غيراستروئيدى، محدودكردن ميزان نمك مصنيط مصرفى،

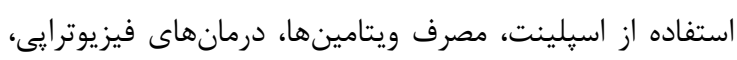

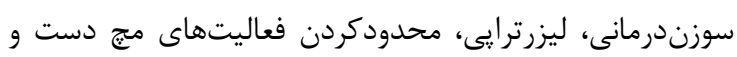

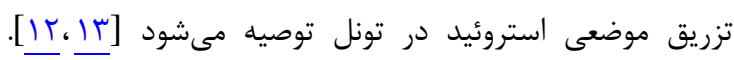

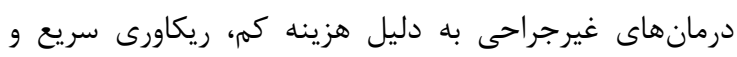

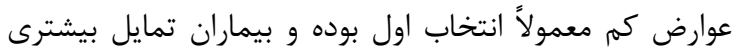


مبتلا به سندرم تونل كارب با شدت متوسط موجب بهبود علائم

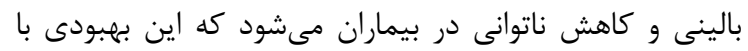

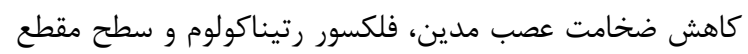
عصب همراه مىباشد. تشكر و قلدر فاذى

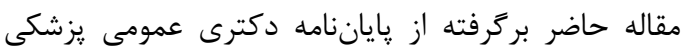

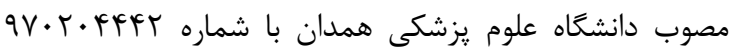
مىباشد. بدينوسيله از حمايتهاى مادى و معنوى مسئولان

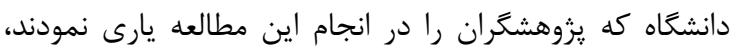
تشكر و قدردانى مى گردد.

تضاد منافع

در اين مطالعه هيجگ گونه تضاد منافعى از سوى نويسندگان كزارش نشده است.

\section{ملاحظات اخلاقى}

مطالعه حاضر داراى تأييديه از كميته اخلاق دانشعاه علوم يزشكى همدان با كد

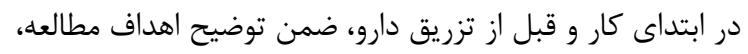

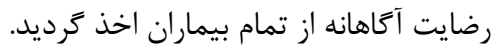

سمهم ذويسنلفكان

نويسنده اول (يزوهشكر اصلى): تدوين جهار جوب كلى طرح،

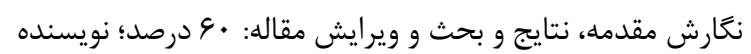

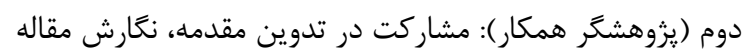

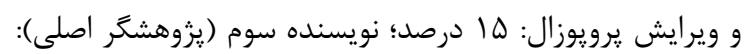

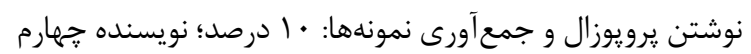
(يزوهشخر اصلى): روشناسى و تحليل

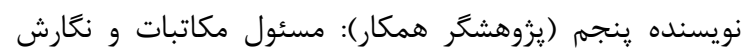
مقاله: · ما درصد

\section{حمايت مالى}

مطالعه حاضر از سوى هيج سازمان يا اركانى گِشتيبانى مالى

نشده است.

\section{REFERENCES}

1. Lee JY, Park Y, Park KD, Lee JK, Lim OK. Effectiveness of ultrasound-guided carpal tunnel injection using in-plane ulnar approach: a prospective, randomized, single-blinded study. Medicine (Baltimore). 2014;93(29):e350. PMID: 25546691 DOI: $10.1097 / \mathrm{MD} .0000000000000350$

2. Lee CH, Choi H, Yoon JS, Kang S. Carpal tunnel syndrome assessment with ultrasonography: a comparison between non-diabetic and diabetic patients. Ann Rehabil Med. 2018;42(1):85-91. PMID: 29560328 DOI: 10.5535/arm. $\underline{2018.42 .1 .85}$

3. Abicalaf CA, de Barros N, Sernik RA, Pimentel BF, BragaBaiak A, Braga L, et al. Ultrasound evaluation of patients with carpal tunnel syndrome before and after endoscopic
اين گروه از داروها در بيماران مبتلا به سندرم تونل كاري، كارايى كمترى دارد [IV]]. هرجند تزريق كورتيكوستروئيدها در كوتاهمدت با بهبود علائم بالينى همراه مىباشد؛ اما كارايى آنها در درازمدت به خوبى مشخص نشده است [11]]. در اين ارتباط، در كارآزمايى بالينى آرمسترانت و همكاران مشاهده شد كه تزريق موضعى بتامتازون در بيمارانى كه عود مكرر علائم بالينى سندرم تونل كارتّ دارند، كارايى مطلوبى ندارد [IV] هرجند تزريق كورتيكوستروئيدها توسط فرد باتجربه آموزشديده يك روش ايمن است؛ اما با عوارض جانبى همراه

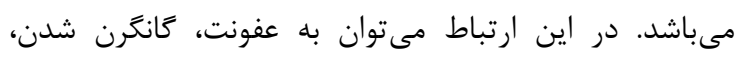
يارگى تاندون، intraneural injection، آتروفى زيرجلدى و دييگمانته شدن اشاره كرد. در مطالعه حاضر بيماران از عارضه

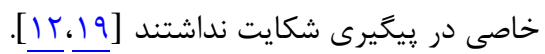
يكى از نتايج قابلانتظار در مطالعه حاضر، شيوع بيشتر ابتلا به سندرم تونل كاري در زنان بود؛ بهَّونهاى كه نسبت ابتلاى زنان جهار برابر بيشتر از مردان بود. در اين راستا، در برخى از

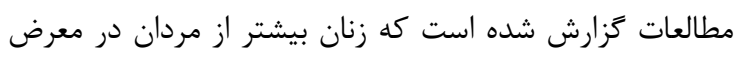

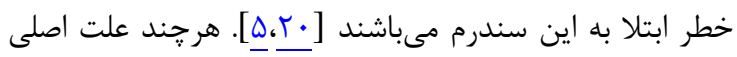
اين سندرم، ايديوياتيك مىباشد؛ اما شيوع بيشتر آن در زنان ممكن است ناشى از باردارى، Body Mass Index) BMI) بالاتر، انجام كارهاى يدى بيشتر و يا مراجعه بيشتر براى پييخيرى درمان باشد.

همراستا با مطالعه حاضر، در ساير مطالعات انجامشده نشان داده شده است كه تزريق موضعى كورتيكوستروئيدها در كوتاهمدت در بيماران مبتلا به سندرم تونل كارت با بهبود علائم بالينى در اين بيماران همراه مىباشد؛ اگرجه انجام مطالعاتى كه كارايى آنها را در درازمدت ييگرى كند، ضرورى به نظر مىرسد.

\section{نتيجبه تيرى}

براساس يافتههاى مطالعه حاضر مىتوان كفت كه تزريق موضعى كورتيكوستروئيدها يكى روش ايمن و آسان است. با ماتهات استفاده از سونوگرافى كه يك روش ساده، غيرتهاجمى، ارزان و در دسترس مىباشد، مىتوان اين بيماران را براى ارزيابى درمان ييخيرى كرد.

نتايج نشان دادند كه تزريق كورتيكوستروئيد در بيماران release of the transverse carpal ligament. Clin Radiol. 2007;62(9):891-4. PMID: 17662738 DOI: $10.1016 /$ j.crad. 2007.01.029

4. Maleki N, Azami A, Anari H, Iranparvar Alamdari M. Value of ultrasonography in the diagnosis of carpal tunnel syndrome confirmed by nerve conduction study. Sci J Kurdistan Univ Med Sci. 2014,19(4):58-66. [Persian]

5. Rezazadeh AL, Bakhtiary AH, Samaei AF, Moghimi JA, Ghorbani RA. Diagnostic value of ultrasonography using median nerve-tunnel index in patients with carpal tunnel syndrome. Koomesh. 2014;15(4):530-40. [Persian]

6. Dalili AR, Mardani-kivi M, Alizadeh A, Hatamian HR, Hoseininejad M, Peyrazm H, et al. Comparison between 
sonography and electrodiagnostic testing in the diagnosis of carpal tunnel syndrome. Anesthesiol Pain. 2011;15(2):43-51. [Persian]

7. Khosrawi S, Emadi M, Mahmoodian AE. Effectiveness of splinting and splinting plus local steroid injection in severe carpal tunnel syndrome: a randomized control clinical trial. Adv Biomed Res. 2016;5:16. PMID: 26962518 DOI: 10.4103/2277-9175.175902

8. Ciftdemir M, Copuroglu C, Ozcan M, Cavdar L. Carpal tunnel syndrome in manual tea harvesters. Eklem Hastalik Cerrahisi. 2013;24(1):12-7. PMID: 23441735 DOI: $10.5606 /$ ehc. 2013.04

9. Shannon H, Rizzolo D. Carpal tunnel syndrome: symptoms, diagnosis, and treatment options. JAAPA. 2012;25(9):22-6. PMID: 22991883 DOI: 10.1097/01720610-201209000$\underline{00005}$

10. Jenkins PJ ,Srikantharajah D, Duckworth AD, Watts AC, McEachan JE. Carpal tunnel syndrome: the association with occupation at a population level. J Hand Surg Eur Vol. 2013;38(1):67-72. PMID: 22832982 DOI: 10.1177/175319 $\underline{3412455790}$

11. Soyupek F, Yesildag A, Kutluhan S, Askin A, Ozden A, Uslusoy GA, et al. Determining the effectiveness of various treatment modalities in carpal tunnel syndrome by ultrasonography and comparing ultrasonographic findings with other outcomes. Rheumatol Int. 2012;32(10):3229-34. PMID: 22038192 DOI: $10.1007 / \mathrm{s} 00296-011-2173-7$

12. Kaile E, Bland JD. Safety of corticosteroid injection for carpal tunnel syndrome. J Hand Surg Eur Vol. 2018; 43(3):296-302. PMID: 29020874 DOI: 10.1177/1753193 $\underline{417734426}$

13. Murtagh J. Injection of the carpal tunnel. Aust Fam Physician. 1991;20(8):1188. PMID: 1953461

14. Marshall S, Tardif G, Ashworth N. Local corticosteroid injection for carpal tunnel syndrome. Cochrane Database Syst Rev. 2007;2:CD001554. PMID: 17443508 DOI: 10.1002/14651858.CD001554.pub2

15. Ustün N, Tok F, Yagz AE, Kizil N, Korkmaz I, Karazincir S, et al. Ultrasound-guided vs blind steroid injections in carpal tunnel syndrome: a single-blind randomized prospective study. Am J Phys Med Rehabil. 2013;92(11):999-1004. PMID: 23811617 DOI: 10.1097/PHM.0b013e31829b4d72

16. Chen PC, Wang LY, Pong YP, Hsin YJ, Liaw MY, Chiang CW. Effectiveness of ultrasound-guided vs direct approach corticosteroid injections for carpal tunnel syndrome: A doubleblind randomized controlled trial. J Rehabil Med. 2018;50(2):200-8. PMID: 29355292 DOI: 10.2340/165019772308

17. Armstrong T, Devor W, Borschel L, Contreras R. Intracarpal steroid injection is safe and effective for short-term management of carpal tunnel syndrome. Muscle Nerve. 2004;29(1):82-8. PMID: 14694502 DOI: 10.1002/mus. 10512

18. Evers S, Bryan AJ, Sanders TL, Gunderson T, Gelfman R, Amadio PC. Corticosteroid injections for carpal tunnel syndrome: long-term follow-up in a population-based cohort. Plast Reconstr Surg. 2017;140(2):338-47. PMID: 28746281 DOI: $10.1097 /$ PRS.0000000000003511

19. Wang PH, Tsai CL, Lee JS, Wu KC, Cheng KI, Jou IM. Effects of topical corticosteroids on the sciatic nerve: an experimental study to adduce the safety in treating carpal tunnel syndrome. J Hand Surg Eur Vol. 2011;36(3):236-43. PMID: 21282223 DOI: $10.1177 / 1753193410390760$

20. Roh YH, Noh JH, Gong HS, Baek GH. Comparative study on the effectiveness of a corticosteroid injection for carpal tunnel syndrome in patients with and without Raynaud's phenomenon. Bone Joint J. 2017;99-B(12):1637-42. PMID: 29212687 DOI: 10.1302/0301-620X.99B12.BJJ-2017-0371.R2 